\title{
Pelvic epidermoid cyst: A rare cause of lower urinary tract symptoms
}

\author{
Pritesh Jain, Dilip Kumar Pal
}

Department of Urology, Institute of Post Graduate Medical Education and Research, Kolkata, West Bengal, India

\section{Correspondence to} Dr Dilip Kumar Pal, urologyipgmer@gmail.com

Accepted 26 April 2018
Check for updates

To cite: Jain P, Pal DK. BMJ Case Rep Published Online First: [please include Day Month Year]. doi:10.1136/ bcr-2017-223258

\section{SUMMARY}

Pelvic retroperitoneum is a bizarre location of an epidermoid cyst and obstructive voiding caused by it even being stranger. Voiding symptoms related to such an abnormal location of cyst are extremely rare and literature that taps into such cases is scarce. We are presenting here a case of 26-year-old man who was presented with obstructive lower urinary tract symptoms and chronic constipation. On evaluation, he was found to have well-defined cyst in pelvic retroperitoneum. Complete excision of the cyst was done; histopathology confirmed it as an epidermoid cyst. His symptoms were completely relieved over a 12-month follow-up.

\section{BACKGROUND}

Epidermoid cysts represent the most common cutaneous cysts, with frequent locations like face, scalp, neck and trunk. Only a few cases have been reported in the literature which shows pelvic location of the epidermoid cyst. Usually asymptomatic, these cysts occasionally lead to compression symptoms due to local mass effect and may displace surrounding organs.

A 26-year-old man presented with obstructive urinary symptoms and constipation attributed to pelvic retroperitoneal cyst makes our case unique in itself. It also highlights the importance of a simple digital rectal examination which helped us in arriving at our diagnosis.

In a young male with lower urinary tract symptoms suspicion of a pelvic mass should be considered as a differential diagnosis, although it is extremely rare.

\section{CASE PRESENTATION}

A 26-year-old man was presented with chief complaints of obstructive voiding symptoms in the form of poor flow, intermittency and straining to void from last 2.5 years. He also had complaint of constipation and his symptoms were increasing gradually. There was no history of urethral instrumentation, sexually transmitted disease, trauma and surgery. General physical examination and focused neurological examination were unremarkable. On digital rectal examination, a soft-to-firm swelling was palpable on the right side of the prostate.

After complete evaluation based on imaging, a diagnosis of pelvic retroperitoneal cyst was made. Based on MRI findings, possibility of an epidermoid cyst was kept and the patient underwent midline laparotomy. Postoperative period was uneventful with rapid improvement in both bladder and bowel symptoms.

\section{INVESTIGATIONS}

The patient was normoglycaemic with normal renal biochemical parameters. Urine analysis was normal. Uroflowmetry revealed straining pattern with decreased maximum flow of urine $(9.8 \mathrm{~mL} / \mathrm{s})$. Ultrasound of abdomen revealed a cyst of approximately $4 \times 5 \mathrm{~cm}$ in periprostatic region arising from the para-prostatic tissue. To further characterise cystic mass, he was evaluated with an MRI of pelvic region which revealed a well circumscribed, mild altered signal intensity lesion (hyperintense in T1 and $\mathrm{T} 2$, isointense to fat in fat-suppressed images) situated in right side of pelvis (figure 1). Dimensions of lesion were $46 \times 35 \times 36 \mathrm{~mm}$. Mass effect was seen in the form of anterosuperior displacement of prostate, seminal vesicle and lateral displacement of rectum.

Histopathological examination of excised cyst showed stratified squamous epithelium-lined wall with a granular layer containing keratin without any nuclear atypia compatible with the diagnosis of a benign epidermoid cyst (figure 2B).

\section{TREATMENT}

Based on MRI findings, a possibility of the epidermoid cyst was kept and the patient underwent midline laparotomy. Intraoperatively, a cystic mass (size $4 \times 5 \mathrm{~cm}$ ) was found in right pelvis abutting prostate, seminal vesicles and displacing rectum towards left (figure 2A). Complete excision of the cyst along with its wall was possible as it was easily separated from surrounding structures.

\section{OUTCOME AND FOLLOW-UP}

Postoperative period was uneventful with rapid improvement in both bladder and bowel symptoms.

\section{DISCUSSION}

An epidermoid cyst is a benign tumour of ectodermal origin formed by desquamation of epithelial cells or implanted ectoderm. ${ }^{1}$ Congenital cysts have embryologic basis of implantation of ectoderm, whereas acquired cyst may be related to trauma or previous surgery. ${ }^{2}$ Common locations of these cysts are on face, scalp, trunk, neck and extremities. However, some exceptional locations have been reported to be in kidney, spleen, brain, bone, etc. ${ }^{23}$ Epidermoid cyst in pelvic retroperitoneum outside major organs is very rare and only few cases have 

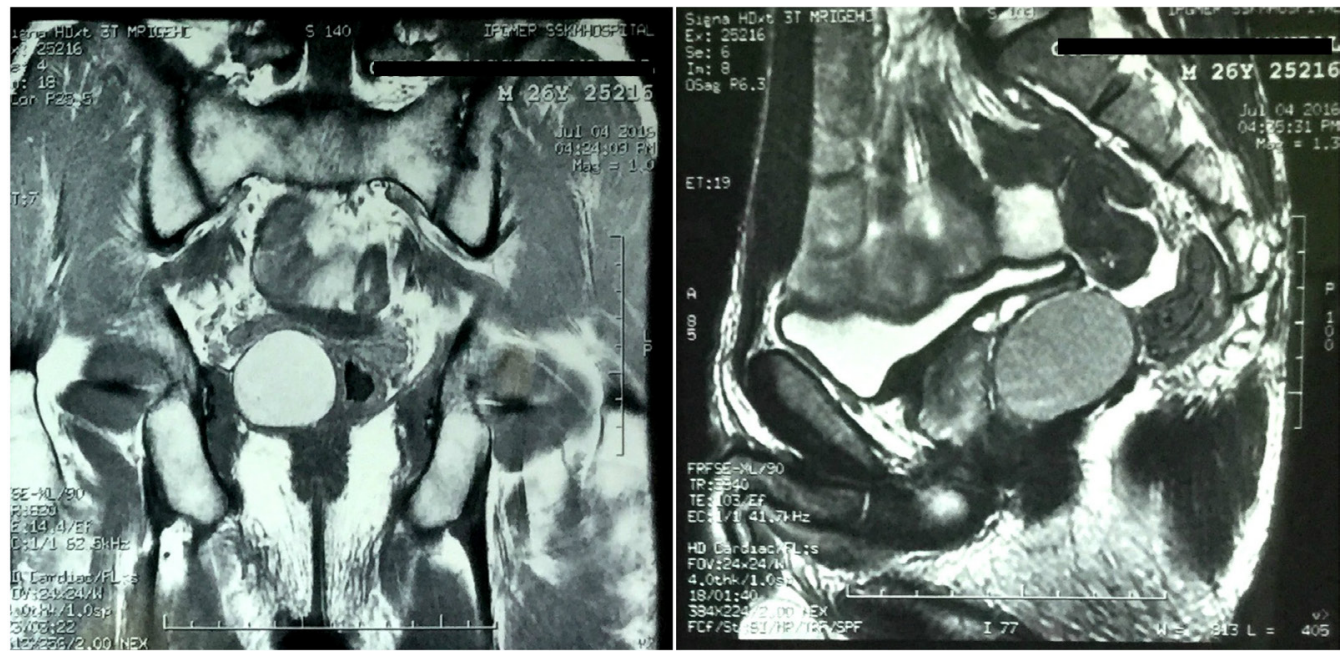

Figure 1 MRI of pelvis region showing epidermoid cyst situated in right side of pelvis with anterosuperior displacement of prostate, seminal vesicle and lateral displacement of rectum.

been reported so far. Pelvic retroperitoneum is less understood than abdominal retroperitoneum, and anatomically, this space can be divided into various spaces like prevesical, perivesical and perirectal. ${ }^{45}$ Epidermoid cysts in pelvic location are usually small and asymptomatic; however, they can enlarge to a significant volume, which can displace and damage surrounding organs. The clinical presentation is variable and depends on its location, size and therefore has mass effect of the cyst and the presence of infection in the cyst. ${ }^{6}$ Infection, bleeding, fistula and malignant conversion are rare complications. ${ }^{78}$ As such, cysts are mostly benign, tumour markers such as cancer antigen-125, carcinoembryonic antigen, etc, have roles only when malignancy is strongly suspected based on clinical examination or on imaging. ${ }^{7}$ In our case, the cyst was located in the right side of the pelvis which was displacing prostate, seminal vesicle and rectum leading to bladder bowel symptoms.

Because of the rarity of epidermoid cyst in the pelvic location, the diagnosis is rarely evoked, and in such cases, imaging with CT or MRI is appropriate to better characterise the lesion. On CT scan, these cysts are characterised by the absence of homogeneous fluid density, which separates it from other common cystic masses like lipoma, fibromas, desmoid tumour, etc. MRI is better than CT in characterisation of these cystic masses due to its intrinsic superior soft tissue contrast and multiplanar imaging capabilities. On MRI, epidermoid cyst appears as

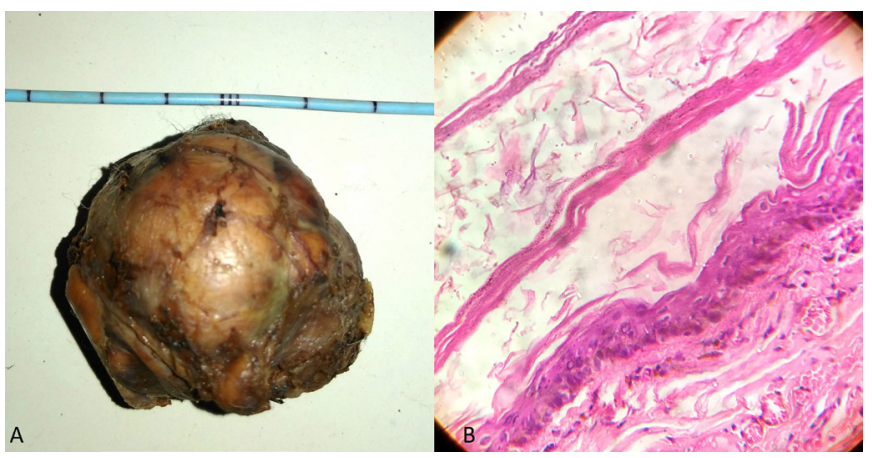

Figure 2 (A) Excised cyst along with its wall (size

$4 \times 5 \mathrm{~cm}$ ). (B) Photomicrograph depicting cyst wall lined by stratified squamous epithelium with a granular layer containing keratin without any nuclear atypia compatible with diagnosis of benign epidermoid cyst. well-circumscribed lesion with heterogeneous signal intensity on both T1-weighted and T2-weighted images due to the variable lipid and protein components. ${ }^{9}$ MRI not only characterises the lesion, but it also helps in surgical planning by defining the extent of the lesion. In our case, MRI was done which provided the details and possibility of an epidermoid cyst with mass effect on surrounding organs. On histopathological examination, these cysts are lined with stratified squamous epithelium that contains a granular layer. Laminated keratin contents are noted inside the cyst. Older cysts may demonstrate calcification, whereas an inflammatory response may be present in cysts that have ruptured. Treatment is required in symptomatic cases or in cases where there is suspicion of harbouring malignancy. Treatment is usually in the form of surgical excision of the cyst along with its wall to prevent recurrence. As pelvic retroperitoneum contains major vessel, nerves along with vital organs like ureter, urinary bladder, rectum, etc, these structures should be carefully dissected to avoid complications. In difficult cases, it is wiser to open the wall and drain cyst. Surgical approach may be via abdominal or combined abdominoperineal route. Some successful laparoscopic excision of a pelvic epidermoid cyst has also been described. ${ }^{10}$

\section{Learning points}

- Extraperitoneal pelvic cysts adjacent to prostate and rectum are extremely rare.

- Differential diagnosis in a young male with voiding symptoms without obvious cause and normal neurological examination should involve diagnosis of pelvic mass although associated infrequently.

- MRI is immensely helpful in characterising the lesion.

- Treatment in such cases is complete surgical excision of cyst along with wall with excellent outcome.

Contributors We certify that we have participated adequately in the intellectual content, conception and design of this work as well as the writing of the manuscript. We take public responsibility for the piece of work and have agreed to have our name listed as a contributor. We believe the manuscript represents valid work. Neither this manuscript nor any other manuscript with substantially similar content under our authorship has been published or is being considered for publication elsewhere, except as described in the cover letter. We certify that all the data collected during the study has been presented in this manuscript and that no data 
from the study has been or will be published separately. We attest that, if requested by the editors, we will provide required information and will cooperate fully in obtaining and providing the information on which the manuscript is based, for examination purposes by the editors or their assignees. We hereby transfer, assign, or otherwise convey all copyright ownership, including any and all rights incidental thereto, exclusively to the BMJ case reports, in the event that such work is published by the BMJ case reports. The BMJ case reports shall own the work, including (1) the copyright, (2) the right to grant permission to republish the article in whole or in part, with or without a fee, (3) the right to produce preprints or reprints and translate into languages other than English for sale or free distribution and (4) the right to republish the work in a collection of articles in any other mechanica or electronic format. Both authors were involved in the conception and design, analysis and interpretation of the data. Both authors were involved in the drafting of the article and revisiting it critically for important intellectual content. DKP shall be involved in the final approval of the version published. Both authors were agreed for accountability of the article and ensures that all questions regarding the accuracy and integrity of the article were investigated and resolved. We give the right to the corresponding author to make necessary changes according to the request of the journal, do the rest of the correspondence on our behalf and he will act as the guarantor for the manuscript on our behalf. If we do not include an acknowledgment, it means that we have not received substantial contribution from such persons and that the name of no contributor has been omitted.

Funding The authors have not declared a specific grant for this research from any funding agency in the public, commercial or not-for-profit sectors.

Competing interests None declared.

Patient consent Obtained.

Provenance and peer review Not commissioned; externally peer reviewed. (c) BMJ Publishing Group Ltd (unless otherwise stated in the text of the article) 2018. All rights reserved. No commercial use is permitted unless otherwise expressly granted.

\section{REFERENCES}

1 Yang DM, Yoon MH, Kim HS, et al. Presacral epidermoid cyst: imaging findings with histopathologic correlation. Abdom Imaging 2001;26:79-82.

2 Fakhir B, Mamouni N, Bouramdane N, et al. A rare case of a giant pelvic retroperitoneal epidermoid cyst. Libyan J Med 2009;4:61.

3 Karaçal N, Topal U, Kutlu N. Popliteal epidermoid cyst: an unusual location. Plast Reconstr Surg 2004;114:830-1.

4 Auh YH, Rubenstein WA, Schneider M, et al. Extraperitoneal paravesical spaces: CT delineation with US correlation. Radiology 1986;159:319-28.

5 Zhang C, Ding ZH, Li GX, et al. Perirectal fascia and spaces: annular distribution pattern around the mesorectum. Dis Colon Rectum 2010;53:1315-22.

6 Shanbhogue AK, Fasih N, Macdonald DB, et al. Uncommon primary pelvic retroperitoneal masses in adults: a pattern-based imaging approach. Radiographics 2012;32:795-817.

7 Hobson KG, Ghaemmaghami V, Roe JP, et al. Tumors of the retrorectal space. Dis Colon Rectum 2005;48:1964-74.

8 Swygert KE, Parrish CA, Cashman RE, et al. Melanoma in situ involving an epidermal inclusion (infundibular) cyst. Am J Dermatopathol 2007;29:564-5.

9 Loock MT, Fornès P, Soyer P, et al. MR imaging features of nongynaecologic cystic lesions of the pelvis. Clin Imaging 2013;37:211-8.

10 Palanivelu C, Rangarajan M, Senthilkumar R, et al. Laparoscopic and perineal excision of an infected "dumb-bell" shaped retrorectal epidermoid cyst. J Laparoendosc Adv Surg Tech A 2008;18:88-92.

Copyright 2018 BMJ Publishing Group. All rights reserved. For permission to reuse any of this content visit

http://group.bmj.com/group/rights-licensing/permissions.

BMJ Case Report Fellows may re-use this article for personal use and teaching without any further permission.

Become a Fellow of BMJ Case Reports today and you can:

- Submit as many cases as you like

- Enjoy fast sympathetic peer review and rapid publication of accepted articles

- Access all the published articles

- Re-use any of the published material for personal use and teaching without further permission

For information on Institutional Fellowships contact consortiasales@bmjgroup.com

Visit casereports.bmj.com for more articles like this and to become a Fellow 